\title{
The visual analogue scale in the assessment of grip strength
}

\author{
W. W. DOWNiE, P. A. LEATHAM, V. M. RHIND, M. E. PICKUP, AND \\ V. WRIGHT
}

From the Clinical Pharmacology Unit, Royal Bath Hospital, Harrogate, North Yorkshire and the Rheumatism Research Unit, University Department of Medicine, The General Infirmary at Leeds

SUMMARY The accuracy of information derived from a visual analogue scale has been assessed bov comparing the measured grip strength of 100 subjects against their estimate of grip strength score on a visual analogue scale. There was relatively poor correlation between the measured and assesse values, suggesting that similar inaccuracies may occur when the scales are used to assess subjective phenomena.

Difficulty in the measurement of subjective phenomena has led to the development of several different scales designed to allow quantitation of symptoms. Simple descriptive scales using 4 or 5 points have been widely used. Numerical rating scales using up to 20 points allow for greater sensitivity than the descriptive scale and, more recently, further sensitivity has been catered for by the introduction of the visual analogue scale (VAS). This last scale is a $10 \mathrm{~cm}$ line whose extreme limits are delineated by perpendicular lines. In order to assist the user of the scale each end carries a verbal description of the intensity of the symptom. The scale may be used horizontally or vertically.

Visual analogue scales have been used widely in rheumatology to assess pain (Huskisson, 1974; Scott and Huskisson, 1976) and function (Huskisson et al., 1976). They have also been widely used in psychiatric practice to evaluate subjective phenomena such as mood, anxiety, and depression. To our knowledge, no attempt has been made to quantitate the accuracy of information derived from visual analogue scales. The present study was designed to test this aspect by comparing the response on a visual analogue scale against a measurable variable, namely grip strength.

\section{Methods}

One hundred subjects participated in the study. The group consisted of 7 healthy individuals and 93 patients with a variety of rheumatic diseases. The

Accepted for publication October 24, 1977

Correspondence to Dr W. W. Downie, Clinical Pharmacology Unit, Royal Bath Hospital, Cornwall Road, Harrogate HG1 2PS grip strength in the dominant hand was estimate clinically by asking the subject to grip, as tightly possible, 3 fingers of a medically qualified observe $p$ The oberver estimated the grip strength in millit metres of mercury $(\mathrm{mm} \mathrm{Hg})$ corresponding to $8 \mathrm{hrol}$ objective method described below and on a 4-p pint verbal scale-very weak, weak, normal, or stres A second observer then measured the grip stren objectively using a sphygmodynamcmeter. The instrument consisted of a sphygmomanometê. cuff folded on itself and taped permanently in position. The cuff was inflated until the column of mercury rose to $30 \mathrm{~mm}$. The patient then squeezed the cuff with the unsupported dominant hand on occasions at intervals of $10 \mathrm{~s}$. The maximum heigh of the mercury column achieved on each occasion was noted and the grip strength taken as the mea of the second and third readings. The scale on the sphygmomanometer was hidden at all times from. the subject under investigation. A third observe asked each subject, after careful explanation, to score his grip strength on a $9 \mathrm{~cm}$ vertical visual analogue scale, the extremes of which were markef as $30 \mathrm{~mm}$ (the initial starting level) and $300 \mathrm{~m}$ m (the maximum score possible using the sphygmoz dynamometer). In addition, each subject was asked to score his grip strength on the 4-point verbal scate previously described. The 3 observers operated independently at all times to ensure the "blin $\mathbb{P}^{2}$ nature of the assessment.

\section{Results}

For the purposes of the analysis the results deriveg from patients' and physician's assessments hat been estimated separately. 
Table 1 Results based on patients' assessments

\begin{tabular}{|c|c|c|c|c|}
\hline & Very weak $(n=6)$ & Weak $(n=34)$ & Normal $(n=43)$ & Strong $(n=17)$ \\
\hline $\begin{array}{l}\text { Measured grip strength }(\mathrm{mm} \mathrm{Hg}) \\
\text { VAS score (mm Hg) } \\
\text { Correlation coefficient (r) } \\
\text { between measured and assessed scores }\end{array}$ & $\begin{array}{l}71 \cdot 2 \pm 18 \cdot 2 \\
115 \cdot 5 \pm 19 \cdot 4 \\
0 \cdot 5651 \\
(P=N S)^{*}\end{array}$ & $\begin{array}{l}100 \cdot 6 \pm 9 \cdot 2 \\
129.4 \pm 8 \cdot 2 \\
0.0219 \\
(P=N S)^{*}\end{array}$ & $\begin{array}{l}198 \cdot 2 \pm 11 \cdot 7 \\
182 \cdot 1 \pm 7 \cdot 7 \\
0 \cdot 4918 \\
(P<0.001)\end{array}$ & $\begin{array}{c}268 \cdot 2 \pm 11 \cdot 4 \\
240 \cdot 4 \pm 11 \cdot 7 \\
0 \cdot 4017 \\
(P=N S)^{*}\end{array}$ \\
\hline
\end{tabular}

*NS = not significant.

Table 2 Results based on physician's assessments

\begin{tabular}{|c|c|c|c|c|}
\hline & Very weak $(n=7)$ & Weak $(n=30)$ & Normal $(n=25)$ & Strong $(n=38)$ \\
\hline $\begin{array}{l}\text { Measured grip strength }(\mathrm{mm} \mathrm{Hg}) \\
\text { Physician's assessment (mm } \mathbf{H g}) \\
\text { Correlation coefficient (r) } \\
\text { between measured and assessed scores }\end{array}$ & $\begin{array}{l}56 \cdot 9 \pm 4 \cdot 9 \\
47 \cdot 1 \pm 4 \cdot 1 \\
0 \cdot 6974 \\
(P<0.05)\end{array}$ & $\begin{array}{l}82 \cdot 4 \pm 4 \cdot 9 \\
79 \cdot 5 \pm 4 \cdot 8 \\
0 \cdot 1942 \\
(P=N S)\end{array}$ & $\begin{array}{c}159.4 \pm 9.6 \\
183 \cdot 2 \pm 8 \cdot 2 \\
0.6126 \\
(P<0.001)\end{array}$ & $\begin{array}{l}265 \cdot 1 \pm 7 \cdot 0 \\
281 \cdot 8 \pm 4 \cdot 3 \\
0 \cdot 5598 \\
(P<0.001)\end{array}$ \\
\hline
\end{tabular}

Table 1 shows the results derived from the patients. In the 6 subjects who considered their grip to be very weak, there was no significant correlation between the measured and assessed scores. Thirty-four patients considered that their grip was weak. In this group no significant correlation was noted between the measured and assessed scores, and there was no significant difference between the measured or the assessed readings in the 'very weak' and 'weak' groups. In 43 subjects the grip was thought to be normal. Both measured and assessed values were significantly greater than the corresponding readings in the 'weak' group $(\mathrm{P}<0.001)$. Within the 'normal' group there was a significant correlation between the measured and assessed grip strength readings. The remaining 17 subjects considered that they had a strong grip. The values obtained were again significantly higher than the corresponding readings in the normal group ( $P<0.001)$. Within the 'strong' group there was no significant correlation between the measured and assessed values.

Table 2 summarises the results derived from the physician's assessments. Seven subjects were thought to have a 'very weak' grip, and a significant correlation was demonstrated between measured and assessed values. In the physician's opinion, 30 subjects were considered to have a weak grip. The measured and estimated values were significantly higher than the corresponding values in the 'very weak' group ( $P<0.001)$. No significant correlation between the measured and assessed values was noted within this group. In 25 subjects the grip was considered to be normal, and both values were significantly higher than in the 'weak' group $(\mathbf{P}<0.001)$. A significant correlation was demonstrated between the measured and assessed values
Table 3 Correlation matrix for pairs of 'measurements'

\begin{tabular}{llll}
\hline & $\begin{array}{l}\text { Physician's } \\
\text { assessment }\end{array}$ & $\begin{array}{l}\text { Measured } \\
\text { grip } \\
\text { strength }\end{array}$ & $\begin{array}{l}\text { Patients' } \\
\text { VAS } \\
\text { score }\end{array}$ \\
\hline Physician's assessment & 1.0000 & $\begin{array}{l}0.9177 \\
(\mathrm{P}<0.001)\end{array}$ & $\begin{array}{l}0.6192 \\
(\mathrm{P}<0.001)\end{array}$ \\
Measured grip strength & & 1.0000 & $\begin{array}{l}0.6385 \\
(\mathrm{P}<0.001) \\
1.0000\end{array}$ \\
Patients' VAS score & & & 1.000 \\
\hline
\end{tabular}

in the 'normal' group. Finally, 38 subjects were thought by the physician to have a 'strong' grip. The values were again significantly higher than in the 'normal' group $(P<0.001)$. Significant correlation was noted between the measured and assessed values in the 'strong' group.

Using the descriptive scales, there was agreement between patient and physician in 59 instances, a difference of one grade in 36 cases, and of 2 grades in only 5 instances. Table 3 shows the overall correlation coefficients for each pair of measurements in all subjects.

\section{Discussion}

The results demonstrate several interesting points. Overall, the physician's performance was superior to that of the patients, as demonstrated by the better separation of the groups and more frequent demonstration of a positive correlation between the assessed and observed values for grip strength. Poor separation of groups (defined on a descriptive basis) using VAS has previously been demonstrated for pain (Downie et al., 1978). The relatively poor performance by patients when evaluated against a quantifiable variable suggests that the use of the VAS in assessment of subjective phenomena may be 
subject to similar inaccuracy. It is, however, generally agreed that the VAS is the most sensitive index for the estimation of pain (Huskisson, 1974).

On the basis of the present study it would seem that more meaningful results might be obtained when using such scales on a serial basis to record changes in symptoms by allowing the patient to have access to his previous scores.

The results also suggest that the qualified physician is capable of making a reliable subjective assessment of at least one of the standard variables used in the assessment of the patient with arthritis.

The Clinical Pharmacology Unit gratefully acknowledges the financial support of Roche Products Ltd.
The authors gratefully acknowledge the secre tarial assistance of Mrs D. K. Smith.

\section{References}

Downie, W. W., Leatham, P. A., Rhind, V. M., Wright, v Branco, J. A., and Anderson, J. A. (1978). Studies wif pain rating scales. Annals of the Rheumatic Diseases, $3 \mathbb{Z}_{2}$ 378-381.

Huskisson, E. C. (1974). Measurement of pain. Lancet, 1127-1131.

Huskisson, E. C., Jones, J., and Scott, P. J. (1976). Applica tion of visual analogue scales to the measurement $\overrightarrow{0 b}$ functional capacity. Rheumatology and Rehabilitation, 19? 185-187.

Scott, J. and Huskisson, E. C. (1976). Graphic representation of pain. Pain, 2, 175-184. 